\title{
Correction to: The Prevalence and Associated Factors of Depression, Anxiety and Stress of First Year Undergraduate Students in a Public Higher Learning Institution in Malaysia
}

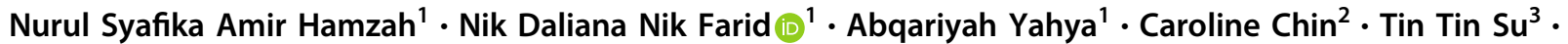 \\ Sanjay Rampal Lekhraj Rampal ${ }^{1} \cdot$ Maznah Dahlui $^{1}$
}

Published online: 14 October 2019

(c) Springer Science+Business Media, LLC, part of Springer Nature 2019

\section{Correction to: Journal of Child and Family Studies} https://doi.org/10.1007/s10826-019-01537-y

The original version of this article unfortunately contained mistakes.

1. On page 7, the heading should read as "Discussions".

2. In Table 4, page 6 at Geographical location, anxiety section under the column heading "Total No (\%)" the value 314 (36.0) should read as 314 (26.0) for the row Central Region.

3. On page 11, the first paragraph starting as "With regards limitations" should read as "With regards to limitations".

The original article can be found online at https://doi.org/10.1007/ s10826-019-01537-y.

Nik Daliana Nik Farid

daliana@ummc.edu.my

1 Department of Social and Preventive Medicine, Faculty of Medicine, University of Malaya, Kuala Lumpur 50603, Malaysia

2 Medical Education and Research Development Unit (MERDU), Faculty of Medicine, University of Malaya, Kuala Lumpur 50603, Malaysia

3 Jeffrey Cheah School of Medicine \& Health Sciences, Monash University Malaysia, Subang Jaya 47500 Selangor, Malaysia 